Maguire, M., Braun, A. and Ball, S. (2015) 'Where you stand depends on where you sit': the social construction of policy enactments in the (English) secondary school' Discourse, Vol. 36(4), pp.485-499.

\title{
'Where you stand depends on where you sit': the social construction of policy enactments in the (English) secondary school
}

\author{
Meg Maguire*, Annette Braun, ${ }^{b}$ and Stephen Ball ${ }^{b}$ \\ ${ }^{a}$ King's College London; ${ }^{b}$ Institute of Education, London, UK
}

\begin{abstract}
Drawing on a study of education policy enactments in four English secondary schools, this paper argues that different 'types' of policies call up different forms of enactments, and that teachers and others who work in schools will have different orientations towards some of these possible ways of 'doing' school. Through exploring the ways in which two main policies are being enacted, 'Behaviour Management' and 'Standards and Attainment', we argue that policy type, power and positionality, space and time constraints, as well as different subjectivities, render policy enactment a more fragile and unstable process than is sometimes documented in policy analysis and implementation studies. Thus, in policy enactment terms, 'where you stand depends on where you sit'.
\end{abstract}

Keywords: policy enactment; policy actors; positionality; policy type; context.

\section{From policy implementation to enactment in schools}

In much writing on education policy, the meaning of policy is frequently either just taken for granted and/or seen as an attempt to 'solve a problem'-what Colebatch (2006, p. 2) refers to as the 'established ways of thinking about policy'. This form of 'normative' policy analysis

... rests on an unspoken presentation of government as a problem-solving being, separate from the society over which it rules ... Government recognises problems and chooses courses of action to deal with them: these courses of action are 'policy'. (Colebatch, 2006a, p. 3)

The problem is that if policy is seen only in these terms, then all the other moments in the processes of policy and policy enactments that go on in schools, and other organisations, become marginalised or go unrecognised. The jumbled, sometimes ambiguous, messy process that is experienced on the ground by policy actors, what Colebatch (2002) calls

\footnotetext{
* Corresponding author: meg.maguire@kcl.ac.uk
} 
the 'policy activity' of negotiations and coalition-building that work to enact various policies, become displaced, invisible and risk going unrecognised in policy analysis.

Even though policy work in social welfare settings has been revitalised through attempts to generate 'joined up thinking' and incorporate more policy actors, policy making at the legislative level is still characterised by instrumentality and hierarchy. In these sorts of accounts, the teacher and 'other adults' working in and around schools, are bleached out of the policy process or positioned as 'implementers'. However, while many policies 'done' in schools are produced by government elites, legislators and sometimes by influential stakeholders, policy making in all its levels and in all its sites also involves 'negotiation, contestation or struggle between different groups who may lie outside the formal machinery of official policy-making' (Ozga, 2000, p. 113). Policy enactment is a process of social, cultural and emotional construction and interpretation-and not all of these processes are reported or interrogated in outcomes-driven studies of policy implementation. Yet, recognising that policy enactments are multi-layered and messy may help in understanding the complicated relationship between making policy and practising policy in complex situated contexts like schools (Colebatch, 2006a).

Policy is detailed and circulated through texts and artefacts and it is interpreted in equally complex and sophisticated ways. Spillane (2004, p. 7) has argued that in what he calls 'conventional accounts' of policy implementation, very often implementation failure gets blamed on policy actors who, it is alleged, choose not to enact the policy reform or who ignore it. His point is that policy work is more complicated and involves what he calls a process of sense-making. That is, policy actors 'use the lenses they have developed through experience to filter their awareness' (p. 7) and interpret these signals. Policy actors' interpretations account for disruptions in practice. In this article, we are taking interpretation to mean the way in which policy actors initially 'read' and respond to policy. This will be situated and contextualised. Does the policy have to be done? Who will enact it? What does it really mean in practical terms? In our view, policy enactment involves creative processes of interpretation and recontextualisation - and this process sometimes involves 'interpretations of interpretations' (Rizvi \& Kemmis, 1987). These interpretations of interpretations are undertaken in senior leadership meetings (the school managers), in department meetings and sometimes by individual teachers. In all this, the space for 'interpretation' varies from policy to policy and sometimes, from person to person, as we shall see. Policies rarely tell you exactly what to do, they rarely dictate or determine practice, but some more than others narrow the range for imaginative responses.

In many of the school-based policy implementation studies, the focus is with implementation as a way of describing how a single policy reform from the centre/top is worked out in practice in schools. These approaches, useful though they are, do not necessarily help with understanding how it is that certain policies, or strands within policies, are selected and who selects them and what alternatives are discarded along the way. They do not illuminate the ways in which policies can be clustered together to form new policy ensembles that can have unintended, or unexpected consequences in schools. They also do not help us understand how and why school leaders and schoolteachers negotiate with, manage, and put sometimes conflicting policies into practice simultaneously. Spillane (2004, p. 6) suggests that what he calls more 'conventional' policy models are often based on rational choice theory. Choices are made based on 
personal assumptions and 'utility maximization'. Spillane's argument is that if this approach is taken, then where policies do not get fully implemented, this is frequently explained as due to the policy being 'muddled or weak, or because it does not fit with the interests of utility-maximizing local officials' (Spillane, 2004, p. 6). He argues that conventional implementation studies conceive of the school itself as a somewhat homogenous and de-contextualised organisation, an undifferentiated 'whole' into which various policies are slipped or filtered into place. Even more crucially, many of these studies assiduously filter out the ways in which policy actors co-generate different policy possibilities (Forester, 2012), particularly in low-stakes policy areas where there may be a little more space for creative attempts at alternative policy enactments.

In this article, we argue that 'enactments' is a theoretically richer concept which better captures the multifaceted ways in which policies are read alongside/against contextual factors, by different sets of policy interpreters, translators and critics (Ball, Maguire \& Braun, 2012). For example, taking enactment, rather than implementation, as our approach to understanding policy work allows us to recognise the ways in which different schools attempt to realise policy through activities such as in-service sessions for teachers or the circulation of assessment data. These policy-driven activities can both fashion and constrain the possibilities of interpretation and the social construction of policy practices within each individual school. Enactments are illustrated by and come out of the 'micro-politics of policy practices through the diverse accounts of situated and entangled practitioners themselves' (Forester, 2012, p. 23). Policy is not 'done' at one point in time, it is always a process of 'becoming'. It is reviewed and revised as well as sometimes dispensed with or sometimes simply just forgotten. There will be multiple subjectivities and positions that will shape how policies are understood, and differences will occur in enactments over time and in different spatial contexts. Enactment then is messy, incomplete and a form of interpretation and intersubjectivity in action.

\section{Heterogeneity and divergent enactments}

In this paper we want to try out some further ideas about policy enactments. Writing is a form of 'thinking aloud' and in this paper, drawing on some of our interview data, we want to elaborate on enactments both theoretically and empirically. As we have said already, a great deal of attention has been paid to how well policies are realised in practice, 'implemented', and less attention has been paid to the ways in which different policy actors in schools, interpret policies in practice in ways that make sense to themselves (Spillane, 2004) but which may not be congruent with other enactments. There may be dominant or official enactments co-existing with informal, less visible and undocumented policy practices. As we have already claimed, some policies are more dominant than others, non-negotiable high-stakes policies that command attention and even compliance, other policies are more fluid. These are different types of policies; they are sometimes fore-grounded, and at other times they are almost invisible. For example, schools may have behaviour policies that are monitored and enforced at the start of the school year but fall away after an initial spurt of activities of monitoring and policing. The wearing of school uniforms would be one example of this type of policy. 
Enacting policies is a process and not a one-off event and in this process some policy actors are more dominant than others; some teachers may be less influenced by particular policy shifts than others. Time and space and positionality and commitments all play a part in the different workings (or not) of policy interpretations in action. As we have argued elsewhere, schools are not of a piece; schools are highly complex and internally differentiated organisations (Braun, Maguire \& Ball, 2010). This heterogeneity lends itself to divergences in the various interpretations of and attention paid to different policies, as we shall see. Quite simply, our point is that depending on the perspectives, values and positions of different types of policy actors and different types of policies, as well as grounded factors of time and place, enactments are contingent, fragile social constructions. Hence 'where you stand depends on where you sit' (Colebatch, 2006, p. 10)—at least to some extent!

\section{The education policy context—in England}

One of the drivers for our work has been the proliferation of education policy in the English context. To a great extent, education policy making in England has been driven by wider international policy imperatives. The international measurement of children's attainments, the production of national league tables and the ranking of education systems by various global institutes (Mortimore, 2013) have fuelled a sense of educational 'crisis' and an international policy reaction that has concentrated on raising standards (Mansell, 2007). This policy move has been in flow for more than the last 20 years or so. In many nation states, attention has been paid to policy work such as curriculum reform, assessment reform and the reform of pre-service teacher education with a view to raising academic attainment. Although it is evidently the case that global education policy has been characterised by dominant discourses of both regulation, standardization, and somewhat contradictorily, diversity, and individualism (Gewirtz \& Cribb, 2009, p. 164), nevertheless, these reforms and restructurings have taken different forms in different national settings.

For instance, in the English setting, there has been a constant steer from central governments towards 'constant improvement in examination results and other performances' (Ball, Maguire \& Braun, 2012, p. 9). As different political parties have come and gone, each administration has produced its own plethora of education policies designed by the central state and passed down to schools. These have covered a wide range of in-school matters; from the safeguarding of children; to healthy eating; reducing school exclusions; reforming the content of the curriculum and the examination system as well as the governance and organisation of schools. There is an assumption that schools will respond quickly to all these demands and policy requirements. However, the complex setting of school life means that schools that are charged with enacting a wide range of policies may have to prioritise what they do. In the classroom, teachers may well be driven by a range of concerns and demands of their own; policies that seem remote may become discarded.

\section{The study}


This paper draws on a study of policy enactments in four English secondary schools, ${ }^{1}$ which aimed to provide a grounded account of the complexities of the relations between policy and practice in schools in a period of incessant change and policy shifts. The study had two main objectives: to develop a theory of policy enactment, and to provide a critical exploration of the differences in the enactment of policy in 'similar' contexts. The study focused on four main issues: (1) the localised nature of policy actions, that is the adjustments and accommodations and conflicts which inflect and mediate policy; (2) the ways in which many different (and sometimes contradictory) policies are simultaneously in circulation and interact with, influence and inhibit one another; (3) the interpretational work of policy actors; and (4), the role of resource differences in limiting, distorting or facilitating responses to policy.

The fieldwork was conducted in four co-educational, non-denominational and nonselective secondary schools, what we have termed 'ordinary schools'. We recognise the challenge of identifying 'ordinary' schools in a time when English schools are under considerable pressure to fabricate themselves as 'extraordinary' — as 'strong' or 'outstanding' in various respects and as 'successful' as far as is possible (Maguire, Perryman, Ball, \& Braun, 2011). The schools are moderately successful with a sound track record of academic achievement, performing at around the national average. They are located in different Local Authorities, including one that is in inner-London (Atwood school), two in different parts of outer-London (George Eliot and Wesley schools), and the fourth in a county town (Campion school). In selecting 'ordinary' schools we sought to avoid 'outstanding' schools or schools that were less pressured to respond to aspects of policy requirements. We also sought to avoid schools that had been identified as having shortcomings; these schools would be under tight scrutiny and would be likely to be concentrating on raising their performance.

In a short paper, it is difficult to provide an adequate contextualisation of each school, and every school is a unique institution. The schools were all co-educational and were still under the control of their local authorities at the time when we were collecting data. That is, they had not become academy schools. Our inner-city case study school (Atwood) has a multi-ethnic, socially mixed student body. One of the outer London schools (George Eliot) sits in an area where there is a large community of families of 'South Asian' heritage, and this is reflected in the school's intake. The other suburban school (Wesley) is ethnically more diverse, although the school is seen as a destination for the 'less academic' children in the area. The school in the county town (Campion) is located in a white, lower middle and working class neighbourhood and this is reflected in their intake. The four schools are all in some way 'typical' for their locality with regards to income levels. Taking the proportions of students on free school meals (FSM) as a proxy for poverty, the FSM percentages in the two suburban schools (George Eliot and Wesley) are broadly in line with the national average of around 15\%. In Campion, FSM is lower and in Atwood, the percentage of FSM students is roughly twice the national average.

We collected four kinds of data: contextualising information from each school; policy texts and artefacts - national, local and school-centred; observations of meetings, training etc.; and semi-structured interviews. In terms of our criteria for data collection of texts and artefactual materials, we collected the key documents that related to our three key policies under investigation (see below) as well as any other texts that seemed relevant or 
were being used in the schools such as Governing Body Reports on performance, school exclusion data, student diaries, staff briefings, etc. We also collected general school brochures, newsletters to parents, and regularly scrutinised each school's website.

We attended a wide range of school meetings such as professional development sessions for staff, governors meetings and department meetings where the researchers wrote up unstructured field notes of what they observed. Interviewees included the headteachers, members of the senior leadership teams, heads of departments and other middle managers, classroom teachers, teaching assistants and non-teaching staff such as bursars and mentors, as well as local authority representatives and relevant 'outsiders' with a link to the school. Questions included topics such as their career trajectories, their views on what policies were high profile in their schools and their perceptions and experiences of our three core policies. Due to time and cost constraints, we concentrated on the perceptions and experiences of adult workers in education, although we acknowledge the policy roles that are played by parents, school governors and school students. The research generated a data set of 93 digitally recorded and transcribed interviews, together with a wide range of documentary and observational data. The study focused on three substantive policies: personalised learning; performance demands in English and mathematics; and behaviour management. These policies were chosen to represent differences such as: (1) their national high-profile; (2) their specificity (particularly in terms of being target-related); (3) their whole school or departmental focus; and (4) their social, achievement or equity goals.

A great deal of data coding and analysis took place in extended team meetings where we shared our interpretations of the data set. We were looking for and attending to examples of different forms of engagement with different kinds of policies. We were looking for discrepancies between different policy actors in our schools as well as differences and similarities between our schools. We also concentrated on the "role of authoritative actors in producing "pre-emptive readings" ' (Ball, Maguire \& Braun, 2012, p. 15).

In the next part of this paper we will explore how different 'types' of policies call up different forms of enactments, and, how those who work in schools may have different orientations towards some of these possible ways of 'doing' school. Enacting policy is context specific and thus, time and place play a part in shaping complex ways in which policies get dealt with - or not! Depending on the type/ level of policy, depending on the social actors who are centrally involved, depending on how policy translations are 'practised', different forms of enactments take place, sometimes within the same departments illustrating Colebatch's (2006b, p. 10) claim that 'where you stand depends on where you sit' so that policy actors are themselves situated as well as being 'sensemakers'.

\section{Different orientations - different positions}

One of the policies that we had selected for exploration was behaviour management in school. In England, student's behaviour, classroom management and 'control' have always been a focus of action by 'policy-makers, schools and their teachers' (Powell \& Tod, 2004, p. 1). Not surprisingly, policy approaches from governments of all political 
persuasions endorse the need for effective classroom control. Head (2007, p. 1) explains that currently 'there is an assumption that if teachers deal with difficult pupil behaviour as a first step, then the young people will learn better'. 'Fixing' behaviour will 'fix' learning.

This new angle is different from that of the more traditional concern with the moral implications of behaviour and the teaching of traditional values through stern discipline ... poor behaviour is emphasised as a significant cause of educational failure. (Wright, 2012, p. 288)

In England, parental anxieties about school discipline, frequently racheted up by the media, continue to be a significant driver for continued action (Steer, 2005, 2009). In consequence, behaviour management has always been a key policy zone for government attempts at micro managing schools - and the churning out of successive reports, strategies and behaviour 'challenges' to schools (DCSF, 2009; Gove, 2012) signal the longevity of this policy imperative. No government can afford to look 'weak' on discipline, and successive governments may want to look tougher than their predecessors. Each school is required to make its own decisions about how they will construct a 'whole school' attempt at enacting 'behaviour for learning' and this aspect of the school is an important part of the school inspection framework. Schools have to be compliant with this policy demand.

However, in the process of enacting disciplinary policies, there are tensions, due in some part to the different orientations and different roles/positions of policy actors in schools. For example, what is commended in one subject area (say, Drama, or Physical Education) may not be seen as appropriate behaviour in other classes. What is regarded as acceptable at one stage/age might be less appropriate in a different phase of schooling. Individual teachers in the same departments may hold contrasting beliefs and values (for example, about the need to support student autonomy and encourage creativity). In one of our schools, George Elliot School, the professional orientations of some members of staff led to different interpretations and practices in enacting behaviour management. This was evidenced in contrasting approaches towards punishment as well as a need to manage consensus within the school community, sometimes at the expense of the students.

I think there is a bit of a discrepancy between members of staff as to what the role of managing behaviour is. Some staff would like, if a student offends, you know, does something wrong, wants to see an instant punishment while other staff are more in favour of rehabilitation and the idea of restorative justice ... And I think that's probably the biggest difficulty with behaviour is trying to make sure that everybody's happy with what takes place. I think some of the sanctions that are given out to students probably aren't in the students' best interests. (Sunny, Pastoral HOD, qualified teacher, George Elliot School)

Reena, a senior pastoral leader (non-teacher) in the same school who had a professional background in counselling and psychotherapeutic approaches to working with young people, had constructed an interpretation and practices that were influenced by her specialist training. Her approach was based on a need for self-awareness and the links between cognition, feelings and actions (Goleman, 1996; Corrie, 2009). She was more concerned to help students understand and 'own' their actions and feelings, rather than 'fixing' any learning difficulties: 
The main challenges, I would say, in my experience, anger management, lack of anger management for a better word. It's sort of, the inappropriate responses of young people, which leads them to make the wrong choice and get into a conflicting situation ... The greater contents of my work is around managing, sort of, temperaments and emotions and, sort of, finding alternative ways of responding, especially to adults. (Reena, Pastoral Head of Year, George Elliot School)

Her work involved encouraging greater self-knowledge and awareness, all which may take longer to develop and may not seem as immediate as more punitive sanctions to some classroom teachers, as she also recognises:

\begin{abstract}
You know, working with them together to resolve the conflict. And I could turn round to a young person and say, you know, 'These things that you've said have really upset this person', you know, 'Can you understand and empathise?' ... I think you find, you know, again I have, sort of, sometimes may have been in people's bad books because of my philosophy on how to work with young people, you know. And I know a lot of teachers, sort of, they want sanctions, sanctions, sanctions. I understand that and, yes, children do have to learn consequences. But, for me, it's not the sanction, it's trying to understand why you've done something and how not to do it again and the sanction would be a part of that, you know. (Reena)
\end{abstract}

Behaviour policies are differently interpreted and enacted by Reena, in part because of the meanings and commitments that she brings to bear in her practice-her professional knowledge and values and emotional response; her situated and subjective professional identity (Zembylas, 2007; Forester, 2012). In practice, 'behaviour for learning' is a key plank of policy and has to be directly addressed in school documentation for auditing and inspection purposes. Senior leadership teams in schools have little choice but to do thisnon-compliance is not possible and their responses will be bound up with their roles as school managers. The orientation is to outcomes and achievement, not to personal growth and development.

\begin{abstract}
We deal with behaviour if it's inappropriate or interfering with a student's achievement, but the focus is all about achievement. We don't want to turn out well-behaved individuals, we want to turn out individuals who have got the skills, qualifications to be able to go on and lead a successful life. (Hazel, Deputy Head of Wesley School)
\end{abstract}

All four schools in our study 'translate' state policy into institutional policy, and what results is a mix of practical and performative responses. However, other levels and different forms of interpretation and practices were being enacted in teams, departments and classrooms. In some subjects, discipline may be more relaxed because of the subject and its environment (the drama studio, for example) while in other settings (perhaps a more hazardous environment such as a science laboratory) control and management may be more overt. Classroom teachers with more day-to-day contact with students may have more time/space in which to negotiate and co-generate behaviour and conduct policy with the students; senior managers are responsible to ensure that the school is compliant with overt (legislated) policy requirements. Thus, behaviour for learning may get enacted in different ways because of different personal and professional orientations as well as because of the different posts of responsibility held by various policy actors in the school. Aspects of behaviour management, that some teachers may regard as petty or less important (dress codes, for instance) may be differently enforced; the ways in which behaviour for learning are enacted may be stronger at the start of the school year or with 
younger students, and more relaxed in the days towards the summer holidays and after examinations have taken place. The point is that the enactment of behaviour policies will be heterogeneous, context dependent, and differently evidenced. Enactment of policies of behaviour in rhetoric and policy documentation will have to have a high visibility, particularly in terms of performance/inspection demands; in practice, enactments may be less high profile, contradictory and sometimes hardly in evidence at all. To a large extent, those policy actors on the ground will construct their enactment practices from their professional commitments, value and pedagogic beliefs, that is, from 'where they stand' (Colebatch, 2006b, p. 10) although divergences may be more possible in the policy area of behaviour management than standards and attainment, a high-stakes policy, for instance.

\section{High stakes policies}

A second policy arena that we had selected for exploration in our project was the "raising standards' agenda. To explain the English context briefly, children are tested at key points throughout their schooling. When they are 16 years old and at the end of compulsory schooling, they sit various tests in a range of secondary school subjects. Success can determine which pathway students will follow (academic or vocational) as well as provide an 'indication' of alleged school effectiveness and performance as results are 'sorted' into published league tables that show how well each school performs. Initially the 'measure' of success was the percentage of students who achieved 5 of these General Certificates of Secondary Education (GCSEs) at grades of between $\mathrm{A}^{*}$ and C. When politicians discovered that this target could be achieved by various forms of 'gaming' (for example, entering students for different examinations that had the equivalence of two or more of these GCSEs), the targets were ratcheted up. In the period when we were in the field, policy was changed to demand that the 5 GCSEs now included English and Mathematics (DfE, 2010). ${ }^{2}$ This policy shift made English and Mathematics the most important subjects at GCSE level-particularly in 'ordinary' schools like ours. It certainly made them the most visible in enactment terms:

This is going to sound terrible but there's a pecking order of subjects these days ... I know that what I'm saying is as head of maths, and that's quite a key role in the school now and that's carrying weight ... you can't escape the fact that maths and English have got certain responsibilities which they have to carry out and sometimes need to be a bit more equal than the other subjects, I think. (Adrian, Head of maths, Campion)

This visibility was 'obvious' to everyone in the school (Ball, Maguire \& Braun, 2012). The consequences of this policy prominence meant that, in our schools at least, these core departments were under a great deal of pressure and concomitantly, were in a 'good' situation in their schools in terms of attracting additional resourcing, additional staff, and favourable time-tabling slots. For example, in George Elliot, where the pressure was on for the mathematics team to raise their game, the school timetable had been changed to allow all the examination cohorts to be taught at the same time each day. This management shift meant that the department could target small groups of students as well as focus on specific mathematical topics with particular students in order to achieve the 
scores they were after. All the other departments knew that this timetabling arrangement (even if it disadvantaged them) was essential; the school needed to achieve in this subject area.

Senior management, and the students know for themselves that maths and English are now the subjects. Do you know what I mean? ... that suddenly maths and English are elevated to a completely different status. (Martin, Head of maths, George Eliot)

I think government knows what it wants, it says English and maths because that's fundamental to learning so we, as a school, we're sort of being pushed in that direction. (Philip, Headteacher, Wesley)

The high visibility and the relentless pressure on these two departments (Perryman et al., 2011) were intense.

You know, Maths, English and science, there's a huge pressure on them because, obviously, being core subjects, you know, if they don't get their $70 \%$ A to C, then it has a big impact on the school's results overall. (Wendy, Head of Social Science, Wesley)

And there's enormous pressure put on us: can they (the students) get a $\mathrm{C}$ grade? And the whole school's reputation is based on [the] percentage of the students, can they get to a $\mathrm{C}$ grade and also how that relates to how many students we're expected to get to a $\mathrm{C}$ grade. (Neil, Deputy Head of English, Wesley)

In this policy arena, there was a direct responsibility for raising standards with which the heads of subject departments were charged with achieving. For the teachers in these departments and for the senior school managers, to some extend there is no-where else to 'stand' except in relation to 'doing' standards better and better! In these high stakes policy arenas, there may be very little choice in terms of the agenda although creative and imaginative responses and leadership may make this work more engaging and pedagogically valuable.

In contrast, this high visibility sometimes meant that other 'parts' of the school and other departments were able to go under the radar to some extent. In some departments, different commitments and values shaped practice in action; some teachers in some subjects were more able to highlight the centrality of their intrinsic disciplinary concerns rather than test grades.

The (new head of department) sees the only purpose of the art department now is to get As to Cs at GCSE ... whereas I always believed we didn't get as good results-we got reasonable results but we didn't get as good results as he thinks he's going to- - but, between you and me, I mean, I believed that kids needed to be able to explore, develop and be artists. (Dave, Art Teacher, Cavendish)

We really want life-long participation ... we have to think about what our kids want because we do want them to play sports after (they leave) school. (Rachael, Head of PE, George Elliot)

One more point - policy enactments are also more/less visible depending on where the departments and staff are physically located in the school campus. For example, many of the centres for supporting students with 'learning difficulties' were tucked away in less accessible and less obvious parts of the building, behind the dining rooms or in a lower 
level of the school. In another school, the sixth form students were housed in a separate building away from the main campus. Physical 'invisibility' can sometimes remove the pressures to enact policies - or at least some of the minor and less high stakes policies. High visibility in some areas can lend a 'cloak of invisibility' to other less central parts of school life. These 'lower-stake' policy settings may also be less susceptible to implementation studies and policy analysis more generally, a point that may well be worth further research.

\section{Policy actors: power, positionality and perspectives}

In our study on policy enactments in secondary schools (Ball, Maguire, \& Braun, 2012, p. 49) we have argued that 'participants and institutions, and agency and interpretation, are all typically undifferentiated' in many of the policy interpretation and implementation studies. In contrast, we found that some teachers are not deeply invested in the policy process at all; they do not take an active part in interpreting and translating policy. Their concerns lie elsewhere. Schools may well be busy enacting a wide number of policies, but this process may simply pass some teachers by - a case of 'now (some of you) see policy and now (some of you) don't'. In cases like this 'where you stand' may simply refer to matters of experience and day to day priorities rather than any more broader issues of values and/or ethics.

Not surprisingly, most junior and newly qualified teachers (NQTs in the English school system) in their first year of teaching, and at times even more experienced teachers, exhibit a form of 'policy dependency' and high levels of compliance. They are looking for guidance and direction. For them, coping in their classroom is the reality that influences the constructions of the meanings of school, policy, teaching and learning. They rely heavily on 'interpretations of (policy) interpretations' (Rizvi \& Kemmis, 1987). They are also to some extent 'shielded' and 'buffered' from policy by more senior colleagues, although this is subject and person dependent. In the secondary school, the subject department is their primary reality and the place where policies become interpreted and conveyed to them:

I think the first term, the Christmas term, was really very difficult to get through, you know. The terms were long and then you start to get to know your students, your students were testing the boundaries and all this lesson planning, behaviour management, everything. (Mai, NQT mathematics, George Elliot)

Different policies and their enactments usually seemed distant from the immediate concerns and perspectives of beginning teachers. The first year in particular was described as a 'blur', a matter of getting by from day to day, and getting very tired. Morgan et al., (2010, p. 191) found that 'while remote structural factors may heavily influence teaching, it is the perception of events at micro-level that impinge most strongly on motivation'. From this position policy is something that comes from 'them'-either the senior leadership team in the school or 'government' or both. Policy work at this level is a matter of muddling through, although almost all of the NQTs reported being well supported by their colleagues and were determined and resilient. National, institutional and 'classroom' policies and priorities, became a veritable 'mash-up' of bits 
and pieces, suggestions for practice, key government discourses and tips from their mentors.

On the one hand, we observed attempts to recruit all teachers as active and creative participants in processes of translating and enacting certain policies, through in-service activities, meetings, observations and 'sharing'. On the other, there was the reliance of new teachers on local policy texts and artefacts and other forms of guidance that could lead to standardisation.

The school's been a lot better, you know, in terms of telling us what you should be doing, you know, on a day-to-day basis and these are the things that we need to prioritise and these are the things we need to focus on. (Aabid, Social Sciences, George Elliot)

Most beginning teachers focus on day-to-day survival and getting their classroom 'right', and responding to what they see as what is expected of them, ' ... you just kind of follow exactly what you're told to do' (Naomi, Religious Education, Atwood). Furthermore, new teachers in England have undertaken their teacher training in a particular regime of accountability constraints, and may not be able to imagine a different way of being a teacher. Gillian, an NQT science teacher in Atwood school found it difficult to remember many of the policies that were being enacted in her school.

Gillian: I'm not massively aware of many policies. Except for the behaviour one. And the homework policy. Which, actually, the homework one slightly-the department homework policy and the school policy possibly slightly contradict each other.

Interviewer: What's the idea of the school's policy?

Gillian: Well, I don't ... I don't really know, actually, I just follow the department one. There has been something about that, about putting grades onto kids' work, like effort grades. I think the school policy is you have to and I don't know what our department policy is, but there was massive discussion about whether we should record them in our planners and not put them on the work. But I don't know what the answer was.

The subject department plays a key role for the beginning teacher, although departments do vary in their coherence and supportiveness and centrality to policy. Departments vary in degrees of their 'earned autonomy' and institutional confidence (see Braun, Maguire \& Ball, 2010), often in relation to their 'output' performances, and being seen as 'well performing' or even 'outstanding'. This cultural status and reputation within the school can have implications for the junior teacher's experience of and engagement with policy. Some subjects, like English, 'carry' well-established subject cultures, and all departments are to an extent 'different worlds' (Siskin, 1991, p. 156) and important organisational sub-structures in the socio-cultural terrain of secondary school. For the beginning teacher, and the more junior members of staff, much policy may simply not be recognised or be visible at all. Much policy may seem distant and unrelated to the pressures of their everyday life; they do not enact policy, they 'follow what they are told' and hope to survive to teach another day. These teachers are at the sharp end of policy delivery, although they may only have a very partial or hazy appreciation of what is entailed. As Gillian says, 'I'm not massively aware of many policies' beyond those that impact her day-to-day life in the classroom. In what she says, we see the way in which 
the social world of the new teacher renders some policies more/less visible, and more/less meaningful - a highly specific, subjective and situated construction of policy enactment.

In this section, we have argued that some policy actors are typically much less invested in policy enactment in the wider school setting as their concerns are driven by their level of experience, their position, and their engagement with their classrooms and students on a day to day basis. However, as a point of comparison and also to illustrate the impact of positionality, it is useful to consider what some of the more senior school managers have to say about policy work. What comes across is their understanding of the wider context as well as their decision-making capacity - their capacity to interpret and define.

One of the staff said, 'Well this is something that I've been talking to (the local school authority/district) about. What do you think? And we said, 'Hold it! Great idea but if we get into that we'll start to crumble at the edges'. (Graeme, Headteacher, Campion)

And what must not be forgotten is that it is not only teachers who interpret and translate policy in schools and have some influence in enactments:

\footnotetext{
We were talking this morning, the head and I, if it really became difficult in terms of staffing. And his view is that you do need a teacher in every classroom ... One of the interesting things obviously is that non-teaching staff cost an awful lot less than teaching staff. (Alicia, School Business Manager, Wesley)
}

\section{Discussion}

In this article, we have argued that the way in which policies are enacted in schools is made more complex by a range of contextualising factors. One over-riding influence relates to the 'type' of policy that is being explored and whether it is mandated or merely recommended. Another aspect that plays into policy enactment is the different positions and perspectives of the local actors. Spillane (2004, p. 6) has argued that conventional policy accounts frequently position local actors as 'interpreting policy to fit their own agenda', and while some of them may do this, others will have a different set of concerns altogether from those enshrined in dominant policy imperatives. In practice, they may well look to other more experienced local actors for guidance and a policy steer. It could be useful for future researchers to explore the ways in which positionality, experience, the allegiances and disciplinary commitments of teachers, as well as loyalties and in-school relations play out in how policies are interpreted and enacted. As Spillane (2004, p. 181) has noted, policy makers need to address the 'tension between the external representations - the new ideas - and local policymakers' and teachers internal representations'. In this paper we have concentrated on one key aspect of what is involved in policy enactment. In some ways, it might be argued that we have simply utilised Spillane's (2004) notion of policy work as a 'sense-making' process; and in many ways, this is what some of our data certainly suggests. However, this sense making is multi-dimensional and other aspects such as biography, teacher identity and positionality, disciplinary cultures, and political perspectives all make up who teachers are and where they stand (Colebatch, 2006b, p. 10). 
In addition, in the school setting, there are always constraints of time and space that influence what happens and the ways in which policy is sometimes left to one side; time and space also shape, to some extent, where it is that teachers 'stand'. Rituals and rites of passage, such as the start and end of each year, the examination period, the annual arrival and departure of staff and students, lend a pattern and rhythm to the annual cycle of the school. Thus, it is not surprising that enacting policy is a complicated and sometimes inchoate process. It is both contingent and specific, situated in time/space and seen as less/more important by different policy actors in schools. Time and space play a crucial role in the when, how, and why of policy enactment. For instance, some policies become very 'tied' to a particular senior leader; when they leave the school, so does their policy portfolio and their particular approach. Some policies start the year as high profile, foregrounded by school leaders; by the end of the year they have faded away and become forgotten. In studies of policy work, this very real dimension of the way schools are actually constructed, performed and produced is sometimes forgotten.

In coming to understand how things are the way they are, Haidt (2012) argues that reason does not always drive social matters; intuitions and emotions can often be just as useful in explaining how and why things get done. In schools, different policy actors have different loyalties, different projects of the self and different sets of personal and professional values and some of this is mediated by their positionality in school. Senior policy actors and middle managers in key departments (English and mathematics) certainly have to be compliant with dominant forms of policy imperatives and have to be able to demonstrate how this is being implemented; other more junior policy actors often have different and more immediate (policy) concerns in their daily life, as we have discussed in this article.

However, and sometimes this is another often forgotten fact in policy studies, there is more to teaching and school life than policy. There are 'discretionary spaces' (Fenwick \& Edwards, 2010, p. 126) in and beyond policy, corners of the school where policy does not reach, bits of practice that are made up of teachers' good ideas or chance or simply the time of the year and the nature of the subject/ discipline. For example, the end of the last term of the year in the English secondary school is always a time for celebration, relaxation after examinations, and outings and festivities like sports days and swimming galas. Time is a key factor in realising policy enactments - or not; and at certain times policies are high profile (discipline at the start of the school year) and then move to the background at other times. In periods where the school is more 'relaxed', this will be reflected in classrooms where students will be engaged in creative or 'fun' activities rather than preparing for examinations. Enactment is about policy realisation, but unlike much policy rhetoric, schools are 'real-time' places where people get tired and where they inevitably pay different kinds of attention to different kinds of policies at different times of the year. For all these sorts of reasons then, 'where you stand' in terms of subject department, pedagogical values, the time of the year, and a range of other biographical factors such as length of service, plays powerfully into 'where you sit' (Colebatch, 2006b, p. 10) and renders policy enactment a more fragile and unstable process than is sometimes imagined. 


\section{Notes}

1 'Policy enactments in the secondary school: theory and practice', ESRC reference: RES -062-23-1484.

2 As we were finishing our fieldwork, the new Conservation Coalition Government changed the attainment goalposts for GCSE; students can now 'gain' an English Baccalaureate (Ebac) if they achieve GCSEs in English, mathematics, sciences, a language and a humanities subject (see Perryman et al., 2011). The inclusion of a language requirement has placed strains on schools, as modern foreign languages are not compulsory in English schools after the age of 14 years.

\section{References}

Ball, S.J., Maguire, M., \& Braun, A. (2012). How schools do policy. Policy enactments in secondary schools. London: Routledge.

Braun, A., Maguire, M., \& Ball, S.J. (2010). Policy enactments in the UK secondary school: Examining policy, practice and school positioning. Journal of Education Policy, 25(4), 547-560.

Colebatch, H.K. (2002). Policy (2 ${ }^{\text {nd }}$ edn.) Buckingham: Open University Press.

Colebatch, H.K. (Ed.). (2006a). Beyond the policy cycle: The policy process in Australia. Sydney: Allen and Unwin.

Colebatch, H.K. (2006b, November). Thinking about policy: Finding the best way. Paper given at GovNet International Conference, Australian National University, 29 November-1 December.

Corrie, C. (2009). Becoming emotionally intelligent ( $2^{\text {nd }}$ edn.). London: Network Continuum.

Department for Education (DfE). (2010). The importance of teaching. London: HMSO.

Department for Children, Schools and Families (DCSF). (2009). Behaviour challenge strategy. Retrieved from: http://www.dcsf.gov.uk/pns/DisplayPN.cgi?pn_id=2009_0171

Fenwick, T., \& Edwards, R. (2010). Actor-network theory in education. London: Routledge.

Forester, J. (2012, July). On the theory and practice of interpretive policy analysis: From the micro-politics of practice to interpretive analysis and theorizing in action. Paper presented at the Interpretive Policy Analysis Conference, Tilburg, The Netherlands, July 5-7, 2012.

Gewirtz, S., \& Cribb, A. (2009). Understanding education: A sociological perspective. Cambridge: Polity Press.

Goleman, D. (1996). Emotional intelligence: Why it can matter more than IQ. London: Bloomsbury.

Gove, M. (2012). Improving behaviour and attendance in schools. Retrieved from: https://www.gov.uk/government/news/new-powers-for-teachers-to-improve-discipline-in-schools

Haidt, J. (2012). The righteous mind. New York, NY: Pantheon Books.

Head, G. (2007). Better learning, better behaviour. Edinburgh: Dunedin Academic Press.

Maguire, M., Perryman, J., Ball, S.J., \& Braun, A. (2011). The ordinary school—What is it? British Journal of Sociology of Education, 32(1), 1-16.

Mansell, W. (2007). Education by numbers. London: Politico.

Morgan, M., Ludlow, L., Kitching, K., O’Leary, M., \& Clarke, A. (2010). What makes teachers tick? Sustaining events in new teachers' lives. British Educational Research Journal, 36(2), 191-208.

Mortimore, P. (2013). Education under siege. Why there is a better alternative. Bristol: Policy Press.

Ozga, J. (2000). Policy research in educational settings: Contested terrain. Buckingham: Open University Press. 
Perryman, J., Ball, S.J., Maguire, M., \& Braun, A. (2011). Life in the pressure cooker-School league tables and English and mathematics teachers: Responses to accountability in a results-driven era. British Journal of Educational Studies, 59(2), 179-195.

Powell, S., \& Tod, J. (2004). A systematic review of how theories explain learning behaviour in school contexts. In Research Evidence in Education Library. London: EPPI-Centre, Social Science Research Unit, Institute of Education.

Rizvi, F., \& Kemmis, S. (1987). Dilemmas of reform. Geelong, Vic: Deakin University Press.

Siskin, L.S. (1991). Realms of knowledge: Academic departments in secondary schools. London: Falmer.

Spillane, J. (2004) Standards deviation; How schools misunderstand education policy. Cambridge, MA; Harvard University Press.

Steer, A. (2005). Learning behaviour: The report of the practitioners' group on school behaviour and discipline. London: DfES.

Steer, A. (2009). Learning behaviour: Lessons learned. A review of behaviour standards and practices in our schools. Nottingham: DCSF.

Wright, A. (2012). Fantasies of empowerment: Mapping neoliberal discourse in the coalition government's schools policy. Journal of Education Policy, 27(3), 279-294.

Zembylas, M. (2007). Emotional ecology: The intersection of emotional knowledge and pedagogical content knowledge in teaching. Teaching and Teacher Education, 23(4), 355-367. 